\title{
Novel mutations in HSF4 cause congenital cataracts in Chinese families
}

\author{
Zongfu Cao ${ }^{2,3,4 \dagger}$, Yihua Zhu ${ }^{5 \dagger}$, Lijuan $\mathrm{Liu}^{6+}$, Shuangqing $\mathrm{Wu}^{7}$, Bing Liư ${ }^{5}$, Jianfu Zhuang ${ }^{8}$, Yi Tong ${ }^{5}$, Xiaole Chen ${ }^{1}$, \\ Yongqing Xie ${ }^{1}$, Kaimei $\mathrm{Nie}^{1}$, Cailing $\mathrm{Lu}^{2,4}, \mathrm{Xu} \mathrm{Ma}^{2,3,4^{*}}$ and Juhua Yang ${ }^{1^{*}}$ (D)
}

\begin{abstract}
Background: Congenital cataract, a kind of cataract presenting at birth or during early childhood, is a leading cause of childhood blindness. To date, more than 30 genes on different chromosomes are known to cause this disorder. This study aimed to identify the HSF4 mutations in a cohort from Chinese families affected with congenital cataracts.

Methods: Forty-two unrelated non-syndromic congenital cataract families and 112 ethnically matched controls from southeast China were recruited from the southeast of China. We employed Sanger sequencing method to discover the variants. To confirm the novel mutations, STR haplotypes were constructed to check the cosegregation with congenital cataract. The pathogenic potential of the novel mutations were assessed using bioinformatics tools including SIFT, Polyphen2, and Human Splicing Finder. The pathogenicity of all the mutations was evaluated by the guidelines of American College of Medical Genetics and InterVar software.
\end{abstract}

Results: No previously reported HSF4 mutations were found in all the congenital cataract families. Five novel HSF4 mutations including c.187 T > C (p.Phe63Leu), c.218G > T (p.Arg73Leu), c.233A > G (p.Tyr78Cys), IVS5 c.233-1G > A and c.314G > C (p.Ser105Thr) were identified in five unrelated families with congenital cataracts, respectively. These mutations co-segregated with all affected individuals in each family were not observed in the unaffected family members or in 112 unrelated controls. All five mutations were categorized to be the disease "pathogenic" according to ACMG guidelines and using InterVar software. Mutations in the HSF4 were responsible for 11.90\% Chinese families with congenital cataracts in our cohort.

Conclusions: In the study, we identified five novel HSF4 mutations in Chinese families with congenital cataracts. Our results expand the spectrum of HSF4 mutations causing congenital cataracts, which may be helpful for the molecular diagnosis of congenital cataracts in the era of precision medicine.

Keywords: Congenital cataracts, Mutation, HSF4, Chinese

\section{Background}

Congenital cataracts $(\mathrm{CC})$ are a kind of cataracts that present at birth or during early childhood, which account for the most important causes of severe visual impairment in the children especially in infants [1]. More than 1 million childhood blindness is resulted from congenital cataracts in Asia, while around 400,000 of whom probably in China. In the developing countries, $7.4-15.3 \%$ of

\footnotetext{
*Correspondence: genetic88@126.com; julian_yang@fjmu.edu.cn

'Zongfu Cao, Yihua Zhu and Lijuan Liu contributed equally to this work.

${ }^{2}$ Graduate School of Peking Union Medical College, Beijing, China

'Biomedical Engineering Center, Fujian Medical University, Fuzhou, Fujian, China

Full list of author information is available at the end of the article
}

childhood blindness results from congenital cataracts. The prevalence of congenital cataracts in children has been estimated about 1-15/10,000 [2]. Prevention of visual impairment caused by congenital cataracts is an important component of the World Health Organization's (WHO) international program for the elimination of avoidable blindness by 2020 [3].

Genetic factors play key roles in the development of congenital cataracts. With the genetic heterogeneity of congenital cataracts, more than 30 genes on different chromosomes are known to cause the disorder, which include crystallins genes, lens specific connexins genes, major intrinsic protein or aquaporine genes, cytoskeletal

(c) The Author(s). 2018 Open Access This article is distributed under the terms of the Creative Commons Attribution 4.0 International License (http://creativecommons.org/licenses/by/4.0/), which permits unrestricted use, distribution, and 
structural proteins genes, paired-like homeodomain transcription factor 3 genes, avian musculoaponeurotic fibrosarcoma, and heat shock transcription factor 4 [4]. The most frequent modes of inheritance are autosomal dominant (AD), autosomal recessive (AR), and then X-linked recessive. Based on our survey in Chinese population, the eighteen genes, containing CRYAA, CRYAB, CRYBA1, CRYBA4, CRYBB1, CRYBB2, CRYBB3, CRYGC, CRYGD, CRYGS, GJA8, GJA3, HSF4, MIP, BFSP2, EPHA2, FYCO1 and PITX3, can be chosen as the candidate genes to screen congenital cataracts.

In this study, 42 unrelated families with congenital cataracts were recruited from Southeast China, and five mutations in the HSF4 (MIM\# 602438, heat shock transcription factor 4) cause congenital cataracts were reported.

\section{Methods}

\section{Subjects and DNA specimens}

As part of a genetic screening program for genetic eye disorders, we collected peripheral blood from 42 families with congenital cataracts and 225 related individuals from the southeast China. All the affected individuals and unaffected relatives in their family were performed ophthalmological examinations by slit lamp photography. The study followed the tenets of the Declaration of Helsinki. Informed consents were obtained from each participant except for the children. For any participants that are under the age of 16, the consent to participate was obtained from their parents or legal guardians. 112 samples from ethnically matched control individuals were obtained prior to the study. The experiments were approved by the Ethics Committee of Fujian Medical University. Total genomic DNA was extracted from whole blood using the Wizard Genomic DNA Purification Kit (Promega, Beijing, China) according to the manufacturer's instructions.

\section{Mutation screening}

Before this study, we had compiled hot-spot regions of cataract-causing mutations. Briefly, 72 mutant exons of 31 pathogenic genes associated with 299 congenital cataract families or sporadic cases have been reported in 210 selected articles. The 72 exons, account for $34.62 \%$ of all the 208 exons in the 31 genes, were ordered by the summary frequency of disease-causing mutations decreasingly across each gene exons, and the top 26 exons in 18 pathogenic genes were selected as the hot-spot mutation regions. The hot-spot regions covered about 80 percentages of mutations in the compiled mutations with only 36.11 percentages (26/ 72 ) of all the mutant exons, and 12.5 percentages (26/208) of all the exons.

All the mutations in the 18 common genes causing congenital cataracts were screened for all the probands of 42 families. These genes including CRYAA, CRYAB, CRYBA1,
CRYBA4, CRYBB1, CRYBB2, CRYBB3, CRYGC, CRYGD, CRYGS, GJA8, GJA3, HSF4, MIP, BFSP2, EPHA2, FYCO1 and PITX3. The selected hot spot exons and splice junctions of these genes were amplified by PCR from genomic DNA. The PCR primers and conditions for HSF4 were listed in Table 1, and that for other genes listed in Additional file 1: Table S1. PCR products were purified and directly sequenced on an ABI 3730XL Automated Sequencer (PE Biosystems, Foster City, CA) using the same PCR primers. Intra-familial segregation analysis was performed after identification of HSF4 mutations in probands. The identified HSF4 mutations were also checked in 112 normal unrelated individuals from the same ethnic background.

\section{Haplotyping analysis}

To validate the co-segregation of the novel mutations, the genotyping was performed with three selected microsatellite markers flanking each corresponding pathogenic gene in available family members. Three microsatellites in HSF4 include D16S3043, D16S3067 and D16S496. Briefly, PCR products from each DNA sample were separated by gel electrophoresis with a fluoresence-based on ABI 3730 automated sequencer (Applied Biosystems) using ROX-500 as the internal lane size standard. The amplified DNA fragment lengths were assigned to allelic sizes with GeneMarker Version 2.4.0 software (SoftGenetics, State College, Pennsylvania, USA). Cyrillic (version 2.1) software was employed to manage the Pedigree and haplotype data.

\section{Bioinformatics analysis}

Mutations description followed the recommendation of the Human Genomic Variation Society (HGVS). The effects of novel missense mutations on the encoded proteins were further evaluated by Polymorphism Phenotyping [5] v2 (PolyPhen-2) and Sorting Intolerant From Tolerant [6] v5.1.1 (SIFT), and the effects of intronic variants on splicing site changes were predicted by the Human Splicing Finder [7] v2.4.1 (HSF). The pathogenicity of all the mutations was evaluated by the standards and guidelines of American College of Medical Genetics and Genomics [8] (ACMG) using InterVar [9] software.

Table 1 The PCR primers and conditions for HSF4 primers

\begin{tabular}{lllll}
\hline Exon & $\begin{array}{l}\text { Primer } \\
\text { name }\end{array}$ & Primer sequence(5'-3') & $\begin{array}{l}\text { Amplicon size } \\
\text { (bp) }\end{array}$ & $\begin{array}{l}\text { PCR } \\
\text { condition }\end{array}$ \\
\hline 4,5 & HSF4e4/ & GGACCCAAGAGTGA & 481 & $58^{\circ} \mathrm{C} / \mathrm{GC}$ \\
& 5F & GCATGA & & \\
& HSFffer1 \\
5R & CCCTCCTCCTCTTI & & \\
\hline
\end{tabular}




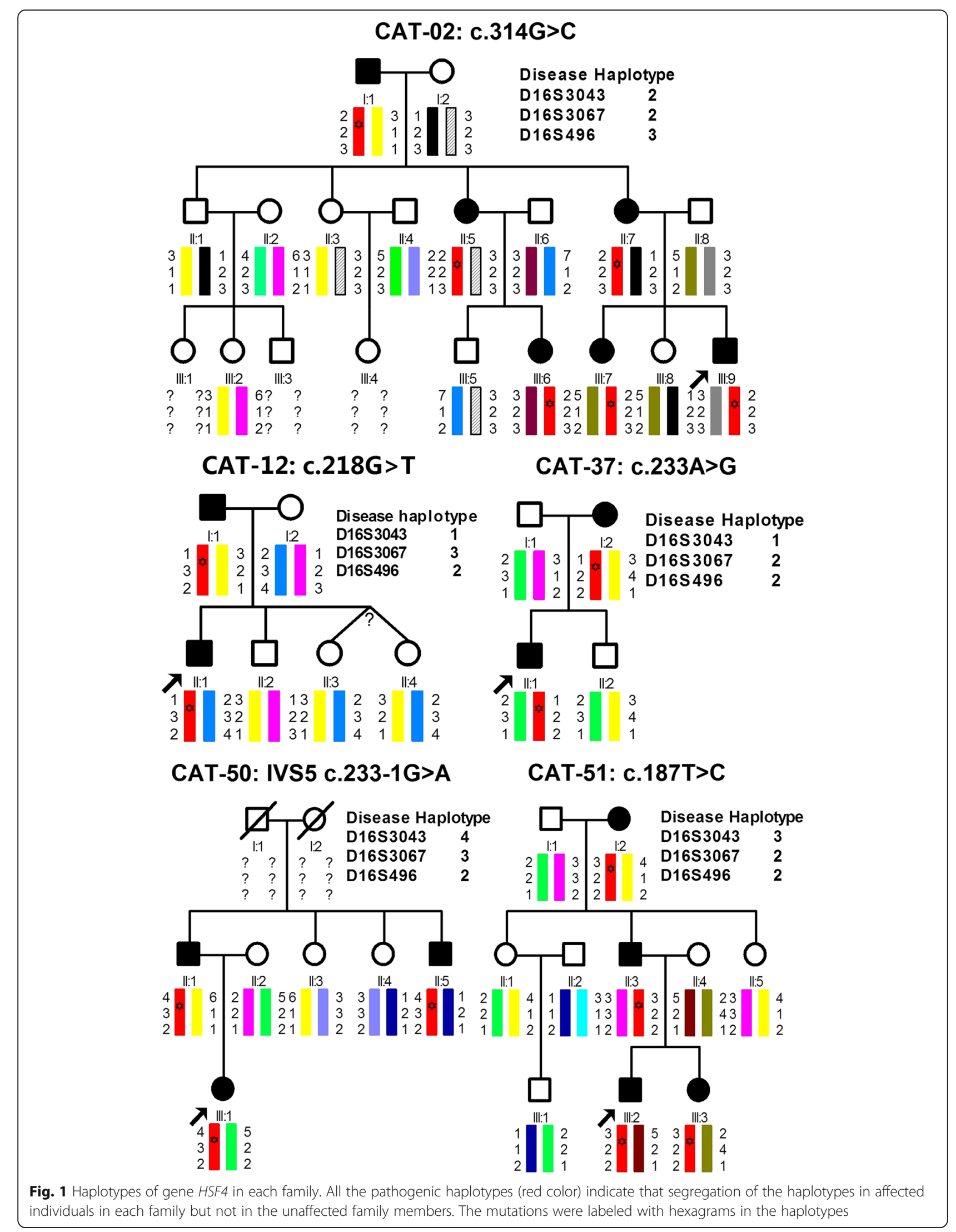




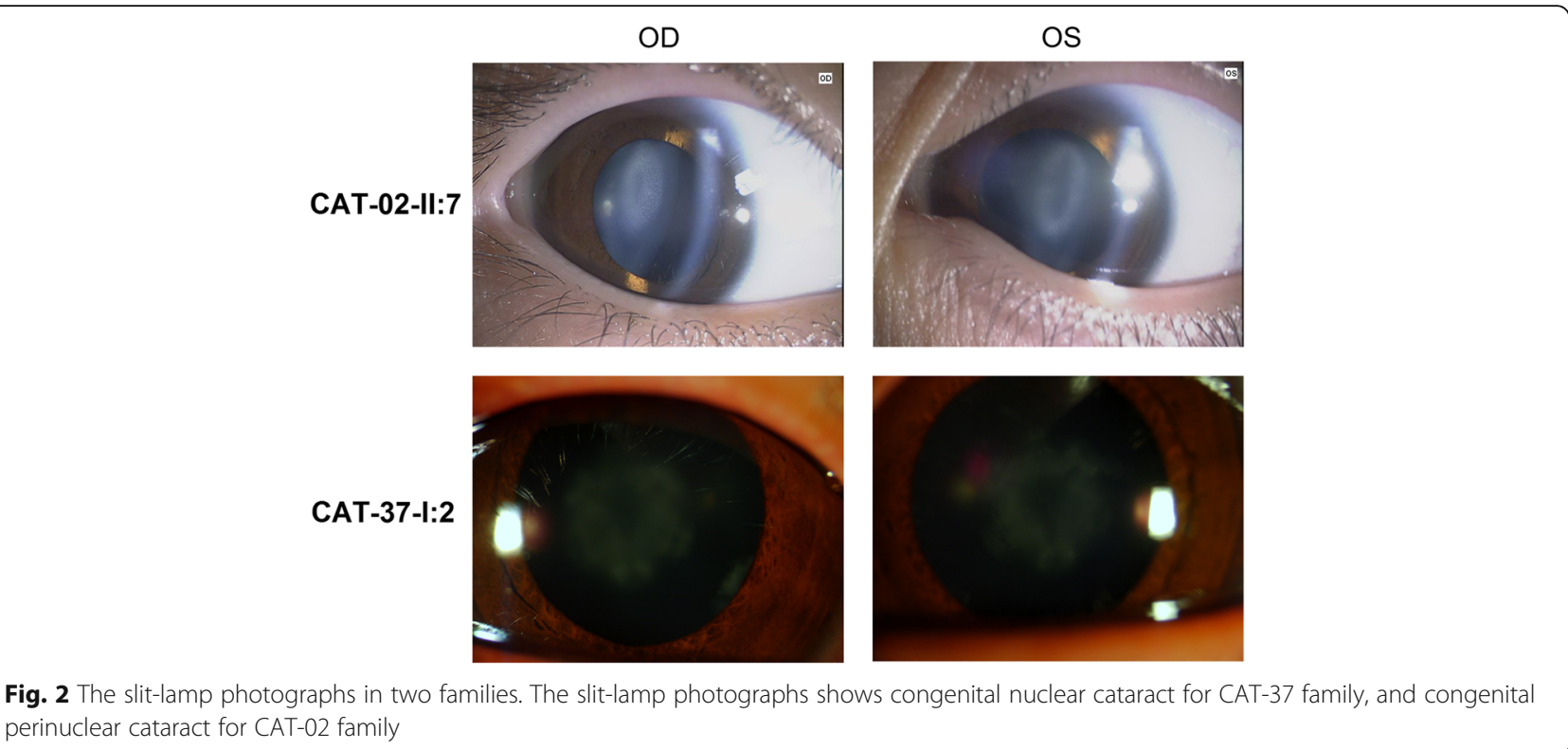

\section{Results}

\section{Clinical description}

The 42 probands are composed of 30 probands from autosomal dominant families, 8 probands with no family history, and 4 isolated cases. In total, 379 individuals were recruited in this study. All the probands were diagnosed as bilateral cataracts at early childhood. No other ophthalmic or systemic diseases were found for all the patients. Five unrelated families were identified HSF4 mutations. The inheritance pattern of those families is AD (Fig. 1). Based on clinical descriptions, family CAT-02 and family CAT-37 have been diagnosed as congenital perinuclear and nuclear cataracts, respectively`. Other three families including
CAT-12, CAT-50 and CAT-51 with congenital total cataracts. The slit-lamp photographs of the patients in two families also showed the phenotype of cataracts (Fig. 2).

\section{Mutation analysis}

In total, five mutations were identified respectively using directly sequencing of the exons and flanking splicing sites of HSF4 (Table 2 and Fig. 3), in five unrelated families with congenital cataracts. There were no variants on other seventeen causing genes detected in these five families. All of the five mutations have not been previously reported. Some mutations identified in other 17 families with congenital cataracts were not reported here. The clinical

Table 2 Classification of HSF4 mutations in this study according to ACMG guideline

\begin{tabular}{|c|c|c|c|c|c|c|c|c|c|c|c|c|c|}
\hline \multirow{2}{*}{$\begin{array}{l}\text { Family } \\
\text { ID }\end{array}$} & \multirow[t]{2}{*}{ Inheritance } & \multirow{2}{*}{$\begin{array}{l}\text { Cataract } \\
\text { Phenotype }\end{array}$} & \multicolumn{5}{|l|}{ Variation } & \multirow{2}{*}{$\begin{array}{l}\text { PVS1 } \\
\text { PVS1 }\end{array}$} & \multirow{2}{*}{$\begin{array}{l}\text { PM } \\
\text { PM1 }\end{array}$} & \multicolumn{3}{|l|}{$P P$} & \multirow[t]{2}{*}{ Classification } \\
\hline & & & $\begin{array}{l}\text { gDNA change } \\
\text { (hg19) }\end{array}$ & $\begin{array}{l}\text { cDNA } \\
\text { change }\end{array}$ & p.change & Status & type & & & PM2 & PP1 & PP3 & \\
\hline CAT-02 & $A D$ & Perinuclear & $\begin{array}{l}\text { g.67199703G> } \\
\text { C }\end{array}$ & c.314G > C & p.Ser105Thr & Hetero & missense & & $Y$ & $Y$ & $Y$ & $Y$ & $\begin{array}{l}\text { Likely } \\
\text { pathogenic }\end{array}$ \\
\hline CAT-12 & $A D$ & Total & $\begin{array}{l}\text { g.67199519G > } \\
\text { T }\end{array}$ & c. $218 G>T$ & p.Arg73Leu & Hetero & missense & & Y & Y & $Y$ & Y & $\begin{array}{l}\text { Likely } \\
\text { pathogenic }\end{array}$ \\
\hline CAT-37 & $A D$ & Nuclear & $\begin{array}{l}g .67199622 A> \\
G\end{array}$ & c. $233 \mathrm{~A}>\mathrm{G}$ & p.Tyr78Cys & Hetero & missense & & Y & Y & $Y$ & Y & $\begin{array}{l}\text { Likely } \\
\text { pathogenic }\end{array}$ \\
\hline CAT-50 & $A D$ & Total & $\begin{array}{l}\text { g.67199621G> } \\
\text { A }\end{array}$ & $\begin{array}{l}\text { IVS5 c.233- } \\
1 G>A\end{array}$ & / & Hetero & $\begin{array}{l}\text { canonical } \\
\text { splice sites }\end{array}$ & Y & Y & $Y$ & $Y$ & $Y$ & Pathogenic \\
\hline CAT-51 & $A D$ & Total & $\begin{array}{l}\text { g.67199488 T> } \\
\text { C }\end{array}$ & c. $187 \mathrm{~T}>\mathrm{C}$ & p.Phe63Leu & Hetero & missense & & Y & Y & $Y$ & Y & $\begin{array}{l}\text { Likely } \\
\text { pathogenic }\end{array}$ \\
\hline
\end{tabular}

$A D$ autosomal dominant, Hetero heterozygosity, Manually adjustments (italic) were performed for the PP3 criteria for all the mutations and all the criteria for c.233-1G > A

PVS1 = The prevalence of the variant in affected individuals is significantly increased compared with the prevalence in controls:

PM1 = Located in a mutational hot spot and/or critical and well-established functional domain (e.g., active site of an enzyme) without benign variation; PM2 = Absent from controls (or at extremely low frequency if recessive) in Exome Sequencing Project, 1000 Genomes Project, or Exome Aggregation Consortium; PP1 = Cosegregation with disease in multiple affected family members in a gene definitively known to cause the disease;

PP3 = Multiple lines of computational evidence support a deleterious effect on the gene or gene product (conservation, evolutionary, splicing impact, etc.) 


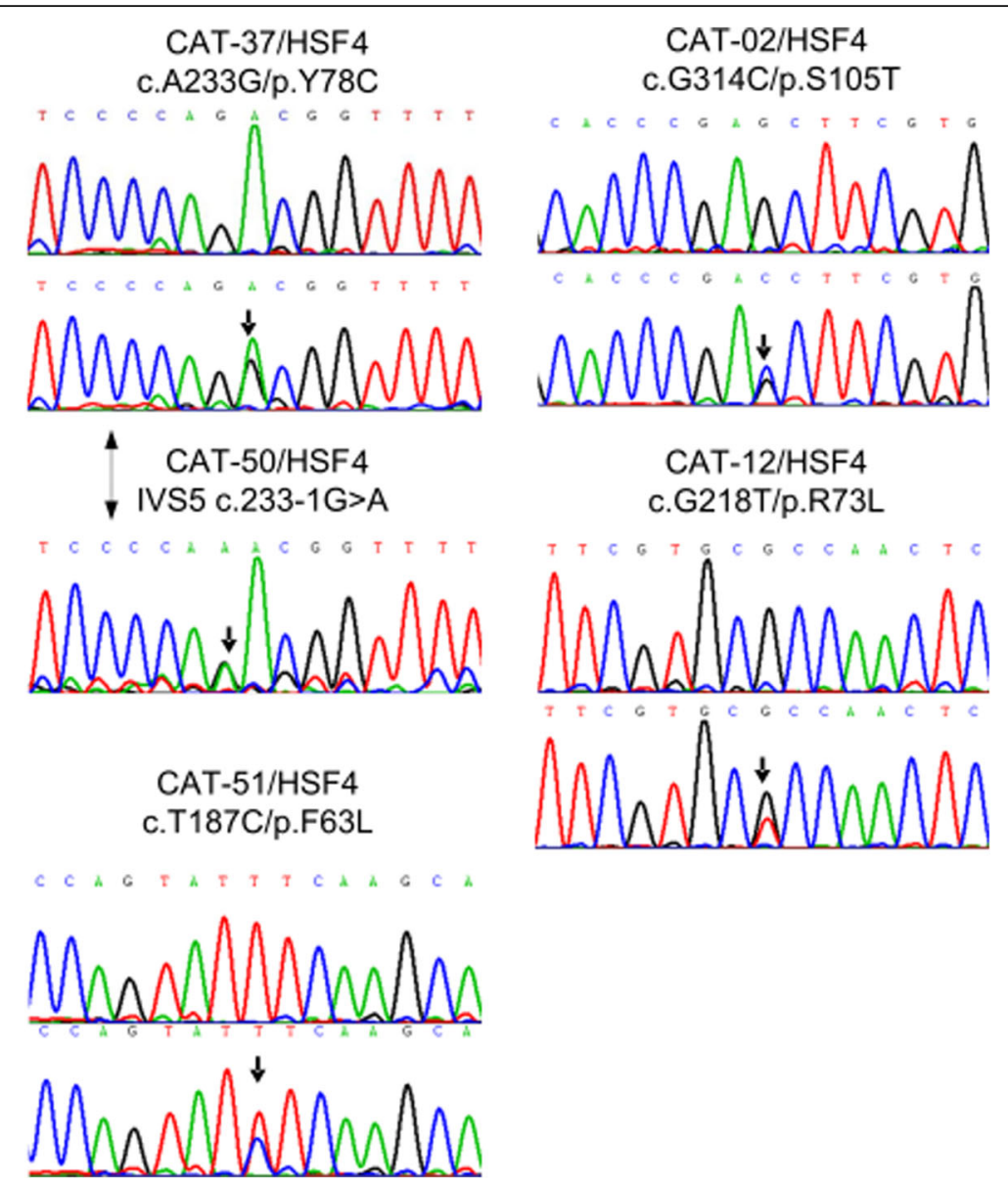

Fig. 3 The 5 novel mutations in HSF4 identified by direct sequencing. The black arrows indicate the mutations in the probands, and the wild type can be seen in the corresponding sequences from normal control

significances of the five mutations were generated by InterVar [9] software on the basis of the criteria recommended by ACMG/AMP guidelines. The process is automatically done firstly, and then follows a manual adjustment to reclassify the mutations for the criteria that InterVar recommends. These five mutations match the criterion of pathogenic moderate 1 (PM1) since all of them are in the hot spot regions. The five mutations were absent in the public databases including 1000 Genomes, ExAC and Genome Aggregation Database, which indicates they match the criterion of pathogenic moderate 2 (PM2). These five mutations were cosegregation with congenital cataracts in each affected family members (Figs. 1 and 3), indicating that they match the criterion of pathogenic supporting 1 (PP1).

In Family CAT-02, the mutation was identified as a c.314G > C missense mutation, where a Serine was replaced by a Threonine at codon 105 (p.Ser105Thr). In Family CAT-12, a c.218G > T substitution was identified, which result in the replacement of an Arginine at position 73 by Leucine (p.Arg73Leu). In Family CAT-37, a c.233A > G missense mutation was identified, which led to Tyrosine at position 78 replaced by Cysteine (p.Tyr78Cys). In Family CAT-51, a c.187 T > C substitution led to Phenylalanine at position 63 replaced by Leucine (p.Phe63Leu). PolyPhen-2 predicted "probably damaging" of all the four variants except for c.233A > G (benign); while the SIFT method predicted "deleterious" for all the four variants except for c.314G > C (tolerated). These predictions indicated that the four variants may have effect on protein function. In Family CAT-50, a IVS5 c.233-1G > A mutation at 1 bp splice sites of the codon 78 is predicted to alter the WT acceptor site and most probably affect splicing by Human Splicing Finder software, which meet the criterion of pathogenic very strong (PVS1).

Finally, all five novel mutations were classified as "likely pathogenic" for congenital cataracts except for IVS5 c.233-1G > A mutation "pathogenic" using InterVar [9] software in accordance with ACMG standards. PM1, PM2 and PP3 were automated for the four missense mutations. The details of each mutation can be seen in the Table 2 . 


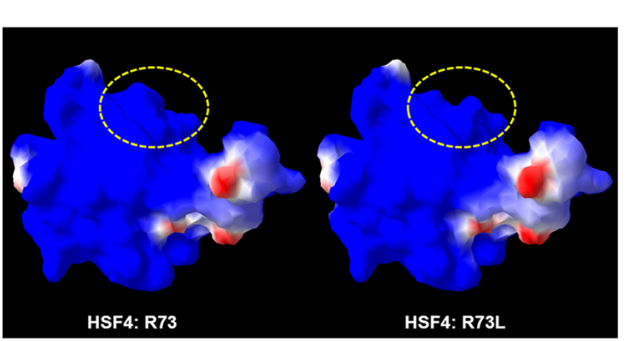

a

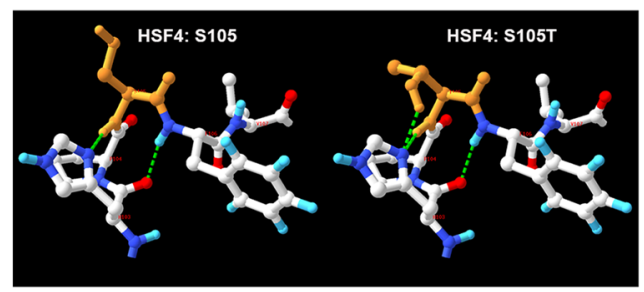

C

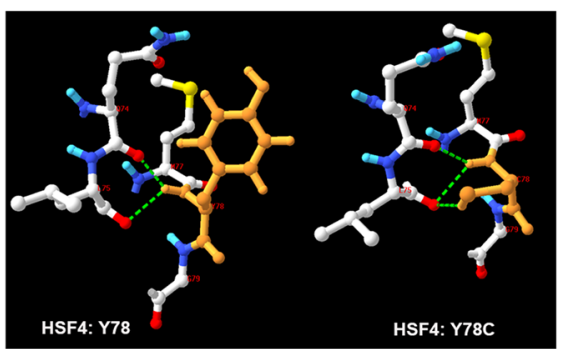

b

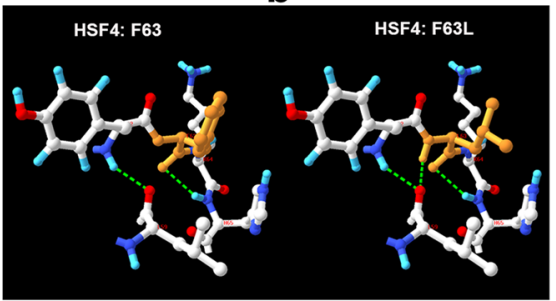

d

Fig. 4 The structural changes of the missense mutations. a Surface change of HSF4:p.R73L. The molecular surface is colored according to electrostatic potential with Swiss-PdbViewer, with red-white-blue corresponding to acidic-neutral-basic potential. b HSF4:p.Y78C gains an H-bond with L75. c HSF4:p.S105 T gains an H-bond with P104. d HSF4:p.F63 L gains an H-bond with L59. Yellow dotted circle represents the region of significant alteration. Green dotted lines indicate potential strong $\mathrm{H}$-bonds

\section{Discussion}

Heat-shock transcription factors (HSFs) activate heat-shock response genes under conditions of elevated temperature and other stress stimuli $[10,11]$. All vertebrate HSFs share the property of lacking the carboxyl-terminal hydrophobic repeat. HSF4, a member of the HSF family, has been found to participate in the negative regulation of DNA binding activity [12]. Several studies presented that HSF4 is required for ocular lens development and fiber cell differentiation [13-15]. Enoki Y et., al have showed that HSF4 can activate

Table 3 Summary of reported mutations in HSF4 associated with congenital cataracts

\begin{tabular}{|c|c|c|c|c|c|}
\hline Exon/Intron & DNAChange & CodingChange & Inheritance & Origin & Reference \\
\hline Ex3 & c. $56 \mathrm{C}>\mathrm{A}$ & p.A19D & $A D$ & China & Bu et al. 2002[18]; ClinVar \\
\hline Ex3 & c.69G $>\mathrm{T}$ & p.K23 N & $A D$ & China & Lv et al. 2014[19] \\
\hline Ex3 & c.89delA & p.D30Afs & / & US & ClinVar \\
\hline Ex4 & C. $187 \mathrm{~T}>\mathrm{C}$ & p.F63 L & $A D$ & China & This study \\
\hline Ex4 & c. $218 \mathrm{G}>\mathrm{A}$ & p.R73H & $A D$ & China & Ke et al. 2006[20] \\
\hline Ex4 & $c .218 G>T$ & p.R73L & $A D$ & China & This study \\
\hline IVS5 & c. $233-1 \mathrm{G}>\mathrm{A}$ & / & $A D$ & China & This study \\
\hline Ex5 & c. $233 \mathrm{~A}>\mathrm{G}$ & p.Y78C & $A D$ & China & This study \\
\hline Ex5 & c. $256 \mathrm{~A}>\mathrm{G}$ & p.186V & $A D$ & China & Bu et al. 2002[18]; ClinVar \\
\hline Ex5 & c.314G >C & p.S105 T & $A D$ & China & This study \\
\hline Ex5 & C.341 T>C & p.L114P & $A D$ & China & Bu et al. 2002[18]; Clinvar \\
\hline Ex5 & $\mathrm{C} .341 \mathrm{~T}>\mathrm{C}$ & p.L114P & $A D$ & Denmark & Hansen et al. 2009[21] \\
\hline Ex5 & c.355C > T & p.R119C & $A D$ & Denmark & Bu et al. 2002[18]; ClinVar \\
\hline Ex5 & c. $355 C>T$ & p.R119C & $A D$ & Denmark & Hansen et al. 2009[21] \\
\hline Ex7 & C. $524 G>C$ & p.R175P & $A R$ & Pakistan & Forshew et al. 2005[22] \\
\hline Ex8 & c.595-599del5bp & p.G199EfsX15 & $A R$ & Pakistan & Forshew et al. 2005[22] \\
\hline IVS11 & c. $1165-2 A>G$ & / & / & US & ClinVar \\
\hline Ex12 & c. $1213 C>T$ & p.R405X & $A R$ & Pakistan & Sajjad et al. 2008[23] \\
\hline IVS12 & c. $1327+4 A>G$ & p.M419GfsX29(delEx14) & $A R$ & Tunisia & Smaoui et al. 2004[24] \\
\hline
\end{tabular}


transcription of genes encoding crystallins and beaded filament structural proteins in lens epithelial cells [16], whereas the mutations in HSF4 gene may inhibit DNA-binding of HSF4, which may result in the loss of lens protein gene expression and cataractogenesis. Mutations in the human HSF4 gene have been reported in both autosomal dominant and recessive cataracts.

In this study, we compiled hot-spot regions of cataractcausing mutations to sequence. All the five mutation reported here are in the hot-spot regions of cataract-causing mutations. Meanwhile, InterVar automatically reported that all the mutations match the criterion of pathogenic moderate 1 (PM1) because all of them are in the hot spot regions. The four missense mutations cause amino acid changes, which maybe eventually result in structural changes of the Heat-shock factor protein 4. Swiss-PdbViewer predicted that the molecular surface may be changed by R73L mutation, while an $\mathrm{H}$-bond is probably obtained to connect Y78C with L75, S105 T with P104, and F63 L with L59, respectively (Fig. 4). The splicing mutation IVS5 c.233-1G > A, was predicted to be broken wild-type acceptor of HSF4 protein, and most probably affecting splicing.

To date, ten mutations of HSF4 gene have been reported to cause congenital cataract and additional two from ClinVar [17] (Table 3), including seven missense mutations (p.A19D, p.K23 N, p.R73H, p.I86V, p.L114P, p.L114P, p.R119C, p.R119C, p.R175P) [18-22], one nonsense mutations (p.R405X) [23], one splice mutation (c.1165-2A > G), and three frame shift mutations (p.D30Afs, p.G199EfsX15, p.M419GfsX29(delEx14) [24]).

Together with five HSF4 mutations reported here, Table 3 showed that HSF4 mutations may be more requent in Chinese than in other world populations. These results suggest that direct screening HSF4 mutations with one pair of primers, co-segregation and bioinformatics analyses, and mutation evaluation based on ACMG guidelines, might be a cost-effective, comprehensive and reliable method for molecular diagnosis of congenital cataracts.

\section{Conclusions}

In summary, we identified five novel mutations in HSF4 causing autosomal dominant congenital cataracts in Chinese families. HSF4 mutations are responsible for $11.9 \%$ (five out of 42) of the families with congenital cataracts in our cohort. Our report extends the spectrum of HSF4 mutations and may be helpful for the genetic diagnosis of congenital cataracts in the era of precision medicine.

\section{Additional file}

Additional file 1: Table S1. The PCR primers and conditions for all the tested genes. The selected hot spot exons and splice junctions of these genes were amplified by PCR from genomic DNA using the primers and conditions. (DOCX 29 kb)

\section{Abbreviations}

ACMG: American College of Medical Genetics and Genomics; AD: Autosomal dominant; AR: Autosomal recessive; CC: Congenital cataracts; HGVS: Human Genomic Variation Society; HSF: Human splicing finder v2.4.1; HSF4: Heat shock transcription factor 4; HSFs: Heat-shock transcription factors (HSFs); PolyPhen-2: Polymorphism phenotyping v2; SIFT: Sorting intolerant from tolerant

Acknowledgements

We are grateful to the patients and their families for participating in this study.

\section{Funding}

The study was supported by National Natural Science Foundation of China (81570870, 81270999), Natural Science Foundation of Fujian Province (2016 J01375), The National Key Research and Development Program of China (2016YFC1000307), Health Science and technology project of Hangzhou (2015A26), and Youth Science and Technology Innovation Grant (2016GJM06).

\section{Availability of data and materials}

The datasets used and/or analysed during the current study available from the corresponding author on reasonable request.

\section{Authors' contributions}

$J Y, C L$, and $X M$ conceived, designed and supervised the study. $Y Z, L L$ and SW rescuited patients and performed clinical examination. $Y Z, L L, S W, B L, J Z$, $Y T, X C, Y X$ and $K N$ acquisition of data, conducted the experiments, performed genetic analysis, provided intellectual input and assisted with the preparation of the manuscript. JY and ZC analyzed and interpreted the data. $J Y$ and ZC wrote the manuscript. JY, XM and ZC revised the manuscript. All authors reviewed the manuscript. All authors have read and approved the final manuscript.

\section{Ethics approval and consent to participate}

This study followed the Declaration of Helsinki and was approved by the ethics committee of Fujian Medical University. Written informed consent was obtained from all of the subjects in this study. For any participants that are under the age of 16 , the consent to participate was obtained from their parents or legal guardians.

Consent for publication

Not applicable.

\section{Competing interests}

The authors declare that they have no competing interests.

\section{Publisher's Note}

Springer Nature remains neutral with regard to jurisdictional claims in published maps and institutional affiliations.

\section{Author details}

${ }^{1}$ Biomedical Engineering Center, Fujian Medical University, Fuzhou, Fujian, China. ${ }^{2}$ Graduate School of Peking Union Medical College, Beijing, China. ${ }^{3}$ National Center for Human Genetics, Beijing, China. ${ }^{4}$ National Human Genetic Resources Center, National Research Institute for Family Planning, Peking Union Medical College, 12 Da-hui-si, Hai Dian, Beijing 100081, China. ${ }^{5}$ Department of Ophthalmology, the First Affiliated Hospital of Fujian Medical University, Fuzhou, Fujian, China. ${ }^{6}$ Fuzhou Southeast Eye Hospital, Fuzhou, Fujian, China. 'Department of Ophthalmology, Hangzhou Red-cross hospital, Zhejiang, Hangzhou, China. ${ }^{8}$ Xiamen Eye Center of Xiamen University, Xiamen, Fujian, China.

Received: 21 March 2018 Accepted: 28 June 2018

Published online: 24 August 2018

\section{References}

1. Deng H, Yuan L. Molecular genetics of congenital nuclear cataract. Eur J Med Genet. 2014;57:113-22.

2. Yi J, Yun J, Li ZK, Xu CT, Pan BR. Epidemiology and molecular genetics of congenital cataracts. Int J Ophthalmol. 2011;4:422-32. 
3. Ackland P. The accomplishments of the global initiative VISION 2020: the right to sight and the focus for the next 8 years of the campaign. Indian J Ophthalmol. 2012;60:380-6.

4. Santana A, Waiswo M. The genetic and molecular basis of congenital cataract. Arq Bras Oftalmol. 2011;74:136-42.

5. Adzhubei IA, Schmidt S, Peshkin L, et al. A method and server for predicting damaging missense mutations. Nat Methods. 2010;7:248-9.

6. Ng PC, Henikoff S. SIFT: predicting amino acid changes that affect protein function. Nucleic Acids Res. 2003;3:3812-4.

7. Desmet FO, Hamroun D, Lalande M, et al. Human splicing finder: an online bioinformatics tool to predict splicing signals. Nucleic Acids Res. 2009:37:e67.

8. Richards S, Aziz N, Bale S, et al. Standards and guidelines for the interpretation of sequence variants: a joint consensus recommendation of the American College of Medical Genetics and Genomics and the Association for Molecular Pathology. Genet Med. 2015;17:405-24.

9. Li Q, Wang K. InterVar: clinical interpretation of genetic variants by the 2015 ACMG-AMP guidelines. Am J Hum Genet. 2017;100:267-80.

10. Akerfelt M, Morimoto Rl, Sistonen L. Heat shock factors: integrators of cell stress, development and lifespan. Nat Rev Mol Cell Biol. 2010;11:545-55.

11. Liang L, Liegel R, Endres B, et al. Functional analysis of the Hsf4(lop11) allele responsible for cataracts in lop11 mice. Mol Vis. 2011;17:3062-71.

12. Nakai A, Tanabe M, Kawazoe Y, et al. HSF4, a new member of the human heat shock factor family which lacks properties of a transcriptional activator. Mol Cell Biol. 1997 Jan;17(1):469-81.

13. Fujimoto $\mathrm{M}$, Izu H, Seki $\mathrm{K}$, et al. HSF4 is required for normal cell growth and differentiation during mouse lens development. EMBO J. 2004:23(21):4297-306.

14. Min JN, Zhang Y, Moskophidis D, Mivechi NF. Unique contribution of heat shock transcription factor 4 in ocular lens development and fiber cell differentiation. Genesis. 2004;40(4):205-17.

15. Gao M, Huang Y, Wang L, et al. HSF4 regulates lens fiber cell differentiation by activating p53 and its downstream regulators. Cell Death Dis. 2017;8(10):e3082.

16. Enoki Y, Mukoda Y, Furutani C, Sakurai H. DNA-binding and transcriptional activities of human HSF4 containing mutations that associate with congenital and age-related cataracts. Biochim Biophys Acta. 2010;1802(9):749-53.

17. Landrum MJ, Lee JM, Benson M, et al. ClinVar: public archive of interpretations of clinically relevant variants. Nucleic Acids Res. 2016;44(D1):D862-8,

18. Bu L, Jin Y, Shi Y, et al. Mutant DNA-binding domain of HSF4 is associated with autosomal dominant lamellar and Marner cataract. Nat Genet. 2002;31:276-8.

19. Lv H, Huang C, Zhang J, et al. A novel HSF4 gene mutation causes autosomaldominant cataracts in a Chinese family. G3 (Bethesda). 2014;4:823-8.

20. Ke T, Wang QK, Ji B, et al. Novel HSF4 mutation causes congenital total white cataract in a Chinese family. Am J Ophthalmol. 2006;142(2):298-303.

21. Hansen L, Mikkelsen A, Nürnberg P, et al. Comprehensive mutational screening in a cohort of Danish families with hereditary congenital cataract. Invest Ophthalmol Vis Sci. 2009:50:3291-303.

22. Forshew T, Johnson CA, Khaliq S, et al. Locus heterogeneity in autosomal recessive congenital cataracts: linkage to 9q and germline HSF4 mutations. Hum Genet. 2005;117:452-9.

23. Sajjad N, Goebel I, Kakar N, et al. A novel HSF4 gene mutation (p.R405X) causing autosomal recessive congenital cataracts in a large consanguineous family from Pakistan. BMC Med Genet. 2008;9:99.

24. Smaoui $\mathrm{N}$, Beltaief $\mathrm{O}$, BenHamed $\mathrm{S}$, et al. A homozygous splice mutation in the HSF4 gene is associated with an autosomal recessive congenital cataract. Invest Ophthalmol Vis Sci. 2004:45:2716-21.

\section{Ready to submit your research? Choose BMC and benefit from:}

- fast, convenient online submission

- thorough peer review by experienced researchers in your field

- rapid publication on acceptance

- support for research data, including large and complex data types

- gold Open Access which fosters wider collaboration and increased citations

- maximum visibility for your research: over $100 \mathrm{M}$ website views per year

At BMC, research is always in progress.

Learn more biomedcentral.com/submissions 